\title{
Deep Integration between Innovative \& Entrepreneurship Education and Specialized Engineering Education
}

\author{
Jun Chu', Rui Jiang', Sijia Zhou² \\ ${ }^{1}$ Institute of Mechanical and Electrical Engineering, Wenzhou University, Wenzhou, China \\ ${ }^{2}$ Institute of Laser and Opto Electronics Manufacturing, Wenzhou University, Wenzhou, China \\ Email: eagleup@wzu.edu.cn, 48113319@qq.com
}

How to cite this paper: Chu, J., Jiang, R., \& Zhou, S. (2019). Deep Integration between Innovative \& Entrepreneurship Education and Specialized Engineering Education. Creative Education, 10, 1561-1572.

https://doi.org/10.4236/ce.2019.107113

Received: May 27, 2019

Accepted: July 16, 2019

Published: July 19, 2019

Copyright $\odot 2019$ by author(s) and Scientific Research Publishing Inc. This work is licensed under the Creative Commons Attribution International License (CC BY 4.0).

http://creativecommons.org/licenses/by/4.0/

\begin{abstract}
The integration between entrepreneurship education and specialized engineering education is a key issue in higher education. This article summarized the research and practice of innovative and entrepreneurial engineering application-oriented talents training pattern for vehicle engineering in Wenzhou University. Deep integration between innovative \& entrepreneurship education and specialized engineering education are composed of the theoretical teaching system, the practice teaching system, the combination of production and research, the entrepreneurship education culture system, and the incubation platform. Course content is optimized through the integration of teaching, scientific research, and social quality resources. Through project-based case teaching and the guaranteed mechanism of the integration of production and education, the content of innovative and entrepreneurship education is permeated to the specialized engineering curriculum. Graduates in the last three years indicate that the reform on specialized engineering education was effective and worth to practice.
\end{abstract}

\section{Keywords}

Innovative \& Entrepreneurship Education, Specialized Engineering Education, Project-Based Case Teaching, Integration of Production and Education

\section{Introduction}

At present, many countries prioritize the innovation and entrepreneurship education of college students. As we know, Babson College, Stanford University, Harvard Business School are the leaders of entrepreneurship education. The entrepre- 
neurship education is a compulsory course or part of a compulsory course in Universities of American, China and about 18 European countries (Meng \& Huang, 2012; Mangan, 1997; Neck \& Greene, 2011; Vetrivel, 2010; Thaddeus \& Beryl, 2010; Kaufman, 2010). College students are the most innovative groups and have a high entrepreneurial potential. Family, society, and universities are the important systems that support the practice of entrepreneurship students. An important mission of colleges and universities is to cultivate the entrepreneurial ability of college students on a large scale through innovation and entrepreneurship education.

College students in the field of engineering and technology tend to have good product ideas, but they lack commercial and market-oriented ideas. Entrepreneurship education can provide intellectual property, business process, marketing, risk capital, and other relevant knowledge for students. Teachers who are engineering professionals should actively conduct entrepreneurship education to further inspire students' entrepreneurial passion. Combining innovation and entrepreneurship education with professional training and including awareness of entrepreneurship in professional courses can encourage students to adopt proper innovation and entrepreneurship practices, so that they can work independently. It is ideally suited to providing the students with personal entrepreneurial capacity to handle problems of uncertainty and complexity in their future work and personal life. They need personal entrepreneurial capacity, including skills in founding commercial organisations in supporting effective entrepreneurial actions (Yu \& Li, 2017).

Despite the rapid growth of entrepreneurship education in Chinese universities, the quality of education is not ideal (Huang, 2014). A survey on entrepreneurship education in colleges and universities found that only $8.88 \%$ of students considered the quality of their education "good"; $55.9 \%$ and $28.12 \%$ of the students described "poor" and "general" effects, respectively; and $7.1 \%$ of the students responded with "I don't know" (Liu \& Deng, 2014). By the end of June 2017, a report from Mycos data (Beijing) Co. Ltd. shows that Chinese college students' entrepreneurship rates in nearly three years were $2.3 \%, 2.9 \%$, and $3 \%$, which are far from the $20 \%$ entrepreneurship rate of American college students (Hao \& Wu, 2017). The following are some of the problems in entrepreneurship education in Chinese colleges and universities:

1) The discipline fundamentals of entrepreneurship education, especially in science and engineering colleges, are weak, characterized by lack of entrepreneurship teachers, an imperfect curriculum system, and weak ideological consciousness (Zhu, Mei, \& Yang, 2012).

2) The mode of innovation and entrepreneurship education is closed, the content is obsolete, and the research method is deficient.

3) A practice platform on innovation and entrepreneurship education is lacking, and guidance and support are ineffective.

4) Innovation and entrepreneurship education is disjointed from professional education. Students are mainly engaged in e-commerce, express delivery, catering, and other service industries, which are not closely integrated with engineer- 
ing education ( $\mathrm{Ni}, 2015)$.

The innovation and entrepreneurship education system must be improved to ensure its effectiveness. In this regard, university engineering specialty may be based on the talent quality orientation of "focusing on practice, enhancing innovation, venturing new business, knowing management and daring to burden responsibility". This concept relies on regional industrial resources and is supported by the integration of production and education, and then transmitted to the project-based case teaching mode. Thus, the innovation and engineering application talent cultivation mode is gradually promoted through the integration of entrepreneurship and professional education.

\section{Method}

For the implementation and development of innovation and entrepreneurship education, it needs to be carried out from several aspects, such as target orientation, education plan, specific practical operation and corresponding guarantee mechanism.

\subsection{Constructing an Innovative Talent Training System for Engineering Application}

Training professionals to cultivate the spirit of innovation and the capacity for innovation and entrepreneurship should be emphasized in the development of entrepreneurship consciousness. With the Wenzhou University vehicle engineering talent cultivation orientation taken as an example, a training program is revised and demonstrated regularly by inviting experts and the representatives of an employer.

According to the local auto manufacturing industry of Wenzhou and the service industry demand for talent, and considering the current situation and characteristics of vehicle engineering, training is necessary to establish the technical backbone of the automobile industry and is vital to become a part of the entrepreneurial elite. Achieving these objectives requires reforming various aspects, including the theoretical teaching system, practice teaching system, entrepreneurship education, cultural system, and guarantee mechanism.

\section{1) Theoretical teaching system}

Innovation and entrepreneurship education should penetrate every stage of theoretical teaching, which includes entrepreneurial perception, learning experience, and the practice of innovation and entrepreneurship. In the course system setting, elective courses on innovation and entrepreneurship for college students vary and can be classified as basic, with regional characteristics, or professional. The content of innovation and entrepreneurship education is integrated into the main professional course.

In the construction and curriculum reform of the professional courses, teachers' scientific research projects are included in the teaching process. Scientific research achievements are condensed into teaching cases. The engineering project case and research are implemented as a teaching method to integrate in- 
novation and entrepreneurship education into professional courses. With the vehicle engineering course taken as an example, teachers' research on automobile parts or automobile technology services is included in the relevant curriculum, which includes vehicle structure, principle, design, manufacturing, marketing, finance, and project management courses. Students will be allowed to participate in product design, marketing, and other sections involved in the formation of a project team.

\section{2) Practice teaching system}

Constructing a practical teaching system and setting up a practice platform and external campus innovative and entrepreneurial practice base for students are necessary in guiding students to conduct innovative practice activities and to participate in entrepreneurship planning and experience.

Vehicle engineering is a technical and practical specialty. Practical and experimental teaching is an important part of innovation and entrepreneurship education. The practice teaching system is created to strengthen the entrepreneurial ability of good students. The system is divided into four levels in accordance with the characteristics of professional practice courses, with emphasis on the students' research and innovation level training.

1) First level (cognitive level): cognitive practice + cognitive experiment.

2) Second level (basic skill training level): basic engineering training + comprehensive experiment + open experiment + curriculum design.

3) Third level (comprehensive training level): experiment on main courses, such as automobile structure, automobile electrical and electronic control technology, automobile detection and fault diagnosis technology, and production practice and other comprehensive practice projects.

4) Fourth level (research and innovation level): independent research and innovation design experiment and scientific research experiment (such as auto part improvement and application), innovative training (such as designing an energy-saving, reduced-emission car), and graduation design.

The integration of knowledge and practical experience is essential for the development and introduction of changes to improve the quality of talent cultivation. It is crucial to support theoretical knowledge with the skills and practical interaction of local government and the business sector. Through the integration of the practice teaching resources of the university, an enterprise, and the government, an experiment teaching platform is established to cultivate engineering ability. A practice teaching platform is created to cultivate professional comprehensive ability. A science and technology innovation platform is formed to hone the engineering innovation ability of students, thereby enabling the creation of an integrated classification system of innovative practice teaching inside and outside of class and school.

Internship is an important part of engineering talent cultivation. Schools and enterprises should communicate and cooperate closely to discuss common business practice details and schedule. In accordance with the actual situation of the enterprise, the teaching effect and students' feedback are considered to adjust 
and enrich the enterprise practice content in a timely manner. The production practice guides students to participate in enterprise management and operation, thereby improving the students' learning effect in the enterprise.

At the same time, by relying on the technology platform, which can be called "smart space", and the sharing platform of the Virtual Design Laboratory, students can apply innovation and entrepreneurship practices, take part in academic competitions, experience a full range of training, absorb the entrepreneurial culture, and cultivate their pioneering spirit and quality.

\section{3) Entrepreneurship education culture system}

The automobile culture festival, entrepreneur forum, automobile club, and other activities create an entrepreneurial cultural atmosphere and enable students to grasp the influence of enterprise education.

Auto-related cultural activities will be conducted, and successful entrepreneurs and outstanding professional graduates will be invited to deliver various lectures and discuss entrepreneurial theories and ideas to shape students' entrepreneurial values and entrepreneurial culture spirit, as well as teach them the norms involved in conducting entrepreneurial activities. Students will be encouraged to form their own community car club. The core of the entrepreneurial culture will be formed, thereby providing incentives for entrepreneurship, persistence, hard work, teamwork, and social responsibility. Failure will be tolerated to influence everyone in this culture, improve the entrepreneurial experience, and enrich the quality of the entrepreneurs' wisdom.

\section{4) Guarantee mechanism}

The guarantee mechanism refers not only to the cooperation and interaction between the school, the government, and the industry, but also to the flexible rules and regulations established by the school with regard to cultivating innovative and entrepreneurial talents.

Taking Wenzhou University as an example, the school has drawn up a series of rules and regulations for cultivating innovative and entrepreneurial talents. An innovation and entrepreneurship recognition mechanism, which effectively protects the innovative entrepreneurship practice of students, was implemented. The rules and regulations include "an innovative action plan for entrepreneurship education", "entrepreneurship education minor/double professional class management measures", "entrepreneurship education and professional education integration of experimental class project management measures", "measures for organization and management of education projects and supporting financial incentive regulation", "management measures of college students' Pioneer Park", "Xin Hu college students' entrepreneurship education fund regulation", "measures for credit management of extracurricular education projects", and "diversified management methods for graduation project (thesis)".

\subsection{Project-Based Case Teaching}

\section{1) Students' projects and extra-curricular activities}

On the basis of the project-based case teaching system, students conduct their 
projects and take part in academic competitions in Maker Space. Given the varying levels of the innovative and entrepreneurship training program for students, a technological innovation mechanism is established step by step, and innovation and entrepreneurial ability is cultivated in many ways.

The content of innovation and entrepreneurship education should gradually form from the theoretical stage to the practical stage, from the subject curriculum to the activity content, and by learning the hidden curriculum content in the process of practice. Such content should actively rely on various innovation and entrepreneurship education platforms in colleges, and encourage the coexistence of different objectives and types of entrepreneurial activities. Diversity is reflected in the content of entrepreneurship, organizational forms, and entrepreneurial environment to adapt to the social demand for diversified entrepreneurial talents.

Students should pay attention to extracurricular activities and entrepreneurial planning supported by project funding, as shown in Figure 1. Teachers provide guidance to students in applying all types of projects actively, such as college students' innovation and entrepreneurship projects, Xin'miao Talents, and other research projects. Students are encouraged to participate in energy-saving motor sports, academic competitions for developing energy-saving products and emission reduction technology, or the tutor's scientific research. Such participation may cultivate the students' pioneering spirit and consciousness. Relying on the creative space of the college, students with similar interests will be invited to form a pilot class and undergo targeted innovation and entrepreneurship education for creative practice teams.

Aside from actively guiding students' innovation and entrepreneurship practice projects, teachers also need to monitor and evaluate the process. The main contents and methods of monitoring and evaluation assessment are shown in Table 1. A set of effective management mechanisms for innovation and entrepreneurship education were formed through operation and management of the pilot class.

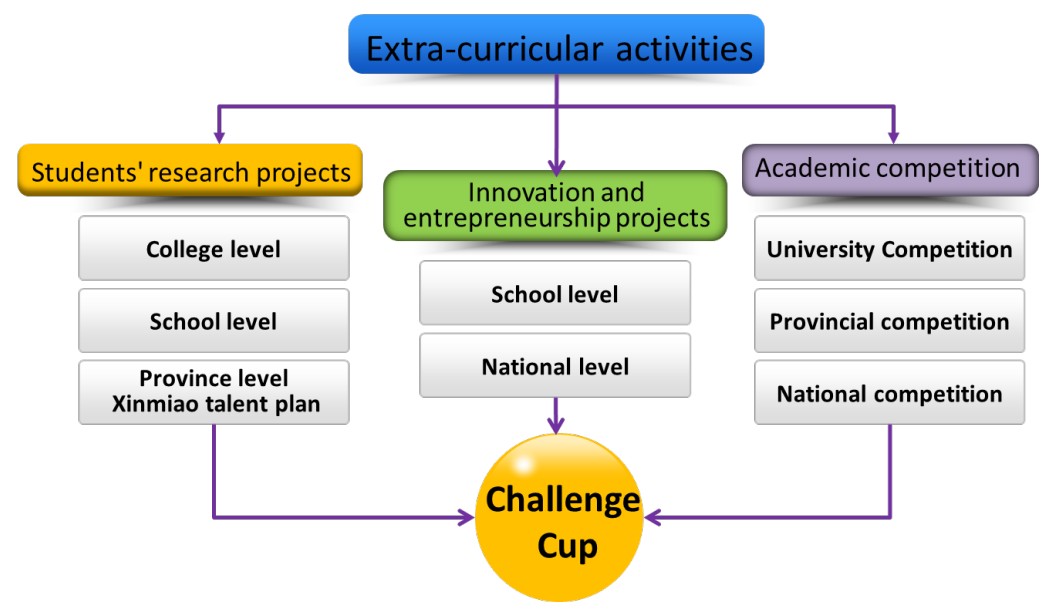

Figure 1. Extracurricular activities based on the project system. 
Table 1. Main contents and methods of monitoring and evaluation assessment.

\begin{tabular}{|c|c|c|c|}
\hline \multicolumn{4}{|c|}{ Main Contents and Methods } \\
\hline Operation results & Open reply & $\begin{array}{l}\text { Design process and } \\
\text { team cooperation }\end{array}$ & Examine \\
\hline Business model & Express theme clearly & Practice log & Function realization \\
\hline Survey report & $\begin{array}{l}\text { Vivid graphic and } \\
\text { presentation design }\end{array}$ & $\begin{array}{l}\text { Discussion } \\
\text { performance }\end{array}$ & Market feedback \\
\hline Business design plan & $\begin{array}{l}\text { Answer questions } \\
\text { accurately and succinctly }\end{array}$ & $\begin{array}{c}\text { Written } \\
\text { communication }\end{array}$ & Entity management \\
\hline $\begin{array}{l}\text { Resource integration and } \\
\text { information collection }\end{array}$ & Behavior patterns & $\begin{array}{l}\text { Oral and interpersonal } \\
\text { communication }\end{array}$ & \\
\hline $\begin{array}{c}\text { Entity } \\
\text { management or not }\end{array}$ & & Problem-solving skills & \\
\hline
\end{tabular}

2) Teachers transform their technological innovation and service into teaching content

Professional teachers involved in local industry research and service advantages will be maximized to transform the teaching process. The practice teaching would be strengthened, and the practice topic can be decomposed from scientific research innovation and technology services. At the same time, attention will be given to the incubation of scientific research, relying on the regional science and technology industrial park and the actual demand of regional industrial production. Experimental material and engineering projects would then be developed. The engineering research institute will also provide an incubation platform for college students (Love \& Wells, 2017).

For example, Wen Ling Research Institute of Wenzhou University was led by a team of professional graduates in 2015. The institute took part in a student summer internship and graduation design, provided technical guidance, and helped students with creating innovative designs. Students were able to participate in the entire product development process, thereby improving their project management ability. If the innovative products have good market prospects, then research institutes can raise funds and contact their partner enterprise to incubate the achievements. Thus, students' design results would be applied in the industry. Such a program fully explores the engineering ability of students. The research institute has become a good student innovation and entrepreneurship practice incubation platform (Wen Ling research institute is affiliated to Institute of laser and opto electronics manufacturing, Wenzhou University, we can get the related information at http://www.imwzu.com/news.php?id=99).

Wenzhou Haichuang Park will be built as a similar platform in South Zhejiang Science and Technology Park. Such platforms will allow an increasing number of student teams to fully develop their potential.

\subsection{Construction of Student Innovation and Entrepreneurship Support System}

\section{1) Building the teaching staff}

The teaching staff for innovation and entrepreneurship education should in- 
clude engineering teachers, academic competitions and project guidance teachers, and entrepreneurial tutors. Engineering teachers should be introduced and trained through the cooperation between industry and education. An interactive cooperation mechanism should be established between teachers and enterprises; each teacher should maintain contact with at least one enterprise. More than one hundred senior engineers may also be involved in the classroom to enhance the overall ability of engineering practice teachers through the "Double Hundred" project.

Entrepreneurship tutors library may include full-time teachers for basic entrepreneurship courses, professional instructors, and student entrepreneurial pioneers; these individuals can provide students with guidance and assistance with business planning and practice.

\section{2) Construction of college students' entrepreneurial platform}

The College of Entrepreneurship and the Students' Pioneer Park and Creation Space were established in Wenzhou University. Wenzhou University specializes in teaching entrepreneurship education, entrepreneurship practice, and entrepreneurship research. An experimentation area focusing on talent training for the integration of professional education and entrepreneurship education was established to cover several specialties, such as vehicle engineering, shoe design, and clothing design.

The construction of an entrepreneurial park, a creative space, and other entrepreneurship platforms supports the incubation of entrepreneurial projects, provides integrated services for entrepreneurial projects, and offers opportunities and guarantees for college students' entrepreneurship practice. The platform offers a full range of professional services, including an open shared entrepreneurial center, appropriate relief rent, and property fees. This platform can also provide one-stop business registration, business project financial management, legal consultation, tax declaration, and intellectual property agency.

\section{Result}

Due to the efforts made by Wenzhou University in the practice of innovation and entrepreneurship education, and the target orientation, education plan, specific practical operation and corresponding guarantee mechanism discussed above are discussed. In the list of Chinese Applied Universities in 2017, Wenzhou University was ranked first. Vehicle engineering was one of the innovation and entrepreneurship pilot majors. They achieved the following results.

\subsection{Student Competition and Practical Operation}

In recent years, vehicle engineering students of Wenzhou University independently produced several single-cylinder energy-saving cars and a pure electric car. These cars competed in the National University Competition successfully for four years in a row. The energy-saving and reduced-emission products won 
the national first prize and third prize, respectively. Some students' products in academic competitions were shown in Figure 2.

\subsection{Student Scientific Research Innovation Projects}

Many projects were completed, such as the Xin'miao Talent Program of Zhejiang Province, the innovative and entrepreneurship training project, and the open laboratory project.

\subsection{Student Entrepreneurship Activities and Companies}

Talent training of the innovation experimentation area was established to integrate innovative and entrepreneurship education and vehicle engineering. In the past three years, more than 10 entrepreneurial practice cases have been conducted by hundreds of students majoring in vehicle engineering. They were mainly engaged in auto part design, electronic commerce, and campus express delivery. The successful business cases include "Aikesai intelligent equipment Wenzhou Co., Ltd.", "Wenzhou Qing Mange e-commerce Ltd.", "Komen studio", "Wenzhou ant e-commerce Ltd.", "Wenzhou Xi Cheng e-commerce Ltd.", and "Jun haoPu'er Tea".

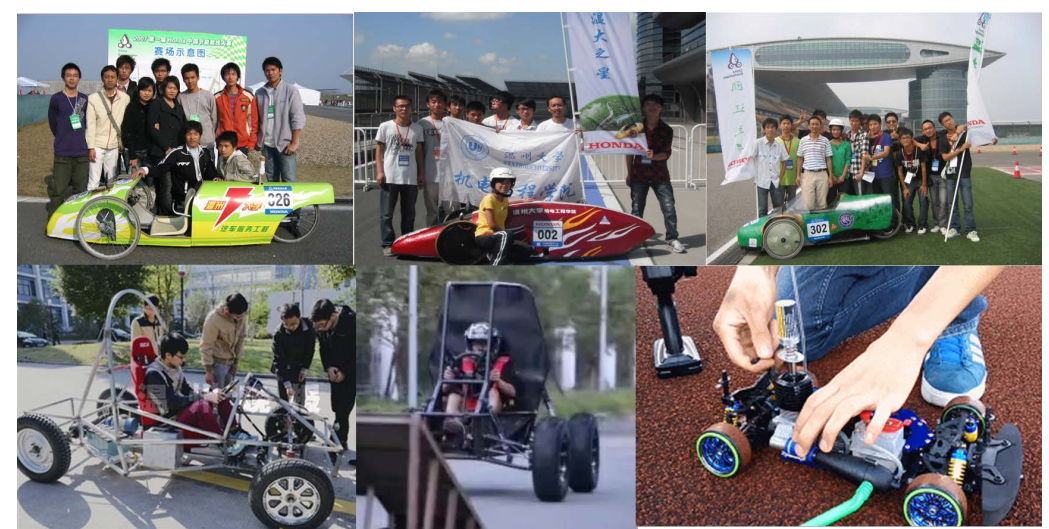

(a)

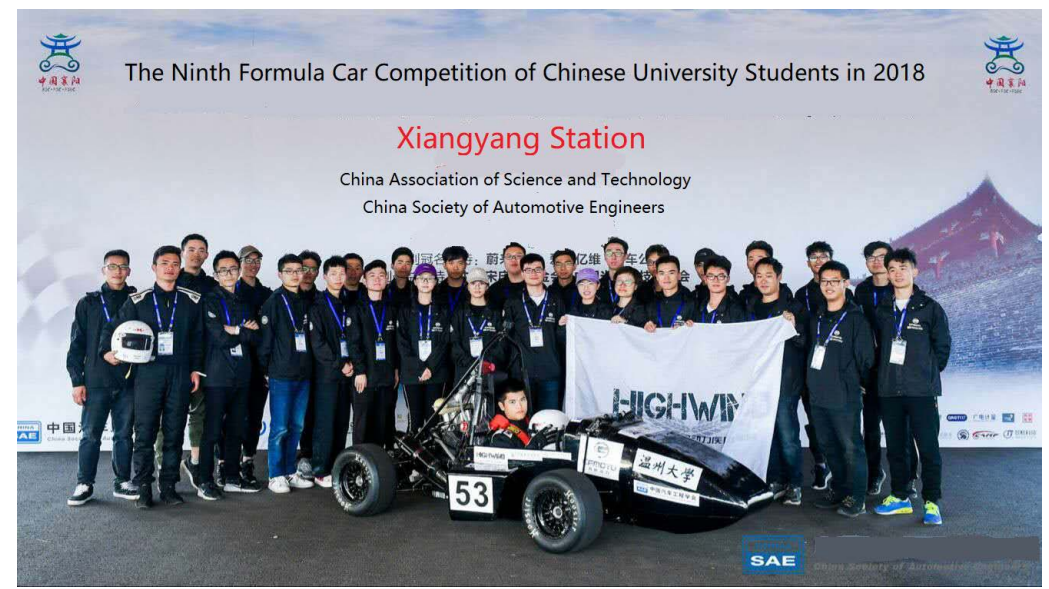

(b)

Figure 2. Some students' products in academic competitions. 


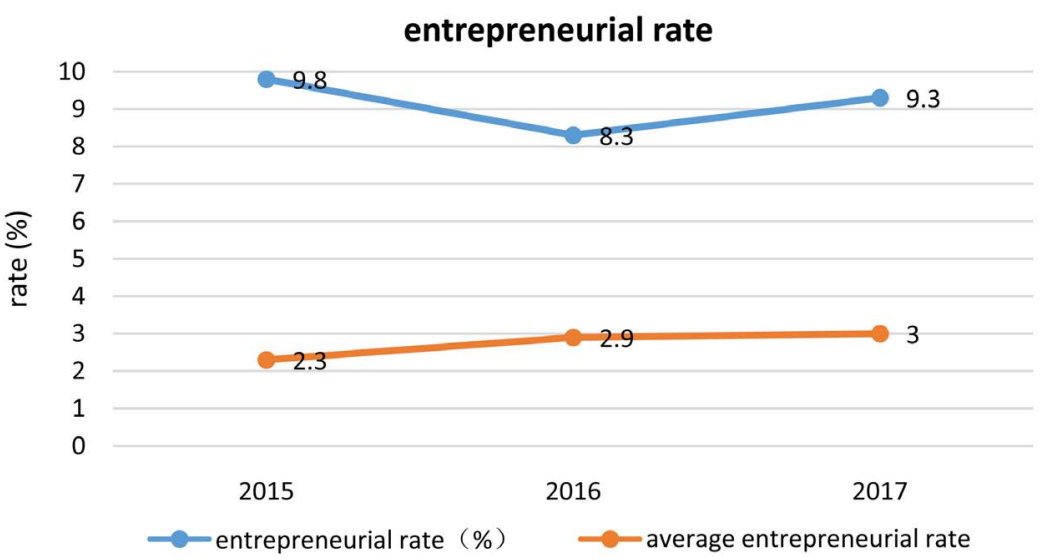

(a)

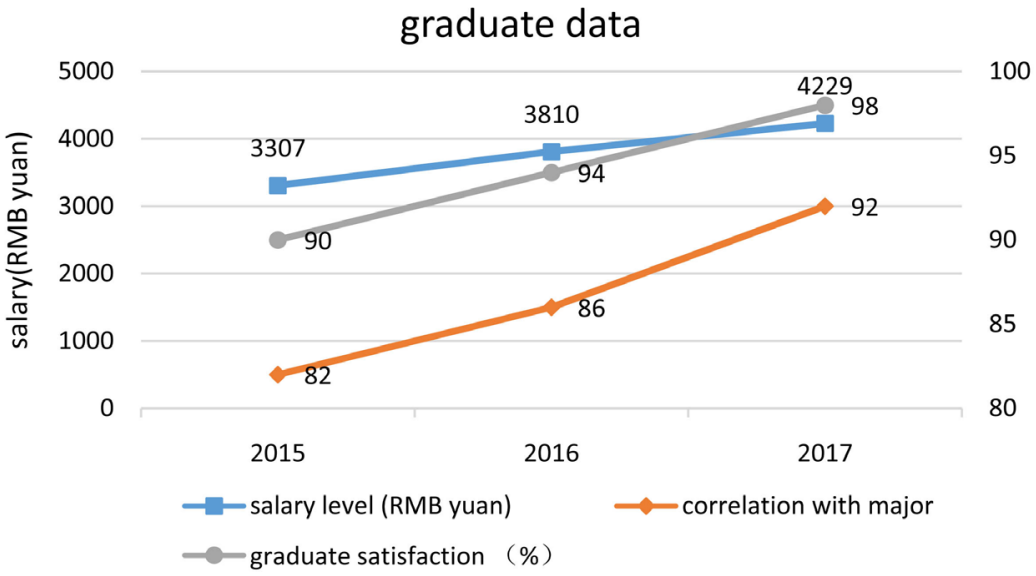

(b)

Figure 3. The recent three years data of vehicle engineering graduates.

\subsection{Employment Quality and Entrepreneurship Rate of Students}

From the official annual report on the employment quality of Wenzhou University graduates, the recent three years data of vehicle engineering graduates were showed in Figure 3. As shown in Figure 3(a), the entrepreneurial rate obviously higher than average of Chinese colleges and Universities. Figure 3(b) shows that graduates' salary and satisfaction were increasing.

\section{Conclusion}

Given the existing problems in innovation and entrepreneurship education, including the weak basic subjects, the imperfect curriculum system, the old content mode, and the lack of a practice platform, the project-based case teaching approach is presented as the foundation of innovative and entrepreneurship education. Entrepreneurship education is driven by innovation through the integration of production and education. Professional teachers' research and service on local industry, students' academic competitions, engineering tutors' involving in the classroom, and other methods all provided the plenty of projects for the students to carry out innovative practice. 
Entrepreneurship education culture and platform provided opportunities and guarantees for the transformation of innovative practice to entrepreneurial practice. A series of innovation and entrepreneurship achievements are produced at Wenzhou University. Innovation and entrepreneurship education is then integrated into professional education in depth. This approach explores a new way of implementing innovation and entrepreneurship education reform for the engineering field.

\section{Acknowledgements}

This article was an outcome of research on the talent training mode of the deep integration of innovation and entrepreneurship education and vehicle engineering. This work was supported by the Zhejiang Province Educational Committee (No. jg20160158); the National Natural Science Foundation of China (No. 51505340).

\section{Conflicts of Interest}

The authors declare no conflicts of interest regarding the publication of this paper.

\section{References}

Hao, J., Wu, A., \& Hou, Y. (2017). Construction and Enlightenment of American Innovation and Entrepreneurship Education System. Research in Higher Engineering Education, 2, 7-12.

Huang, Z. X. (2014). The Transformation and Development of Local Universities' Entrepreneurship Education: Based on the Comparative Analysis of Two Universities. Research in Higher Engineering Education, 6, 141-146.

Kaufman (2010). The Kaufman Panel on Entrepreneurship Curriculum in Higher Education: Entrepreneurship in American Higher Education.

Liu, W., \& Deng, Z. C. (2014). Survey on Present Situation and Policy Suggestion of Innovation Entrepreneurship Education in Universities. Education Science, 30, 79-84.

Love, T. S., \& Wells, J. G. (2017). Examining Correlations between Preparation Experiences of US Technology and Engineering Educators and Their Teaching of Science Content and Practices. International Journal of Technology and Design Education, 28, $1-22$.

Mangan, K. S. (1997). Many Business Schools Add Classes on Entrepreneurship. The Chronicle of Higher Education, 43, 8-9.

Meng, X. X., \& Huang, W. J. (2012). The American Entrepreneurship Education and its Enlightenment on China. China Higher Education Research, 10, 62-65.

Neck, H. M., \& Greene, P. G. (2011). Entrepreneurship Education: Known Worlds and New Frontiers. Journal of Small Business Management, 49, 55-70. https://doi.org/10.1111/j.1540-627X.2010.00314.x

Ni, H. (2015). Basic Connotation and Implementation Models of Social Entrepreneurship Education. Research in Higher Engineering Education, 1, 62-66.

Thaddeus, M., \& Beryl, M. (2010). Adding Entrepreneurship to the General Education Curriculum. North Carolina A \& T State University, No. 8. 
Vetrivel, S C. (2010). Entrepreneurship and Education: A Missing Key in Development Theory and Practice. Advances in Management, 3, 18-24.

Wen Ling Research Institute, Wenzhou University. http://www.imwzu.com/news.php?id=99

Yu, X. Y., Li, D., \& Wu, L. Q. (2017). Study on Project Participation of Innovation and Entrepreneurship Education in Universities by Taking the Innovative Entrepreneurship Training Program of as an Example. Revista de la Facultad de Ingeniería, 32, 742-748.

Zhu, X. Y., Mei, W. H., \& Yang, C. (2012). Problems and Strategies of Constructing Faculty Team for Entrepreneurship Education in Higher Educational Institutions in China. China Higher Education Research, 9, 82-85. 